EXTENDED REPORT

\title{
Refraction and keratometry in 40 week old premature (corrected age) and term infants
}

\author{
M Snir, R Friling, D Weinberger, I Sherf, R Axer-Siegel
}

Br J Ophthalmol 2004;88:900-904. doi: 10.1136/bjo.2003.037499

See end of article for
authors' affiliations
.....................
Correspondence to:
M Snir, MD, Pediatric
Ophthalmology Unit,
Schneider Children's
Medical Center of Israel,
14 Kaplan Street, Petah
Tiqva 49202 , Israel;
moshesnir@hotmail.com
Accepted for publication
1 December 2003

.....................

\begin{abstract}
Aim: To compare refraction and keratometry readings between premature and term babies at 40 weeks' postconceptional age (PCA), and the possible effect of birth weight (BW) and gestational age (GA) on ocular parameters.

Methods: 33 preterm babies hospitalised in the neonatal unit between January and March 2002 were matched with 33 term babies born within the same period and hospitalised in the same unit. The preterm group underwent funduscopy at 4-5 weeks after delivery. Ophthalmic examination at 40 weeks' PCA included cycloplegic retinoscopy, funduscopy, and keratometric measurements. Mean and standard deviation of refraction, astigmatic power (plus cylinder), axis of astigmatism, and keratometric reading were calculated and compared between groups and correlated with BW and GA in the premature babies. Results: Retinopathy of prematurity (ROP) stage 1 or 2 was noted in $88 \%$ of the premature babies on the first funduscopy examination, but only in $36 \%$ by the corrected age of 40 weeks. Statistically significant between groups differences were found for cycloplegic refraction ( $p=0.02$ for both eyes) and keratometry $(p=0.001$ for both eyes). GA and BW had no impact on the refractive and keratometric findings in the preterm babies.

Conclusions: Babies with mild ROP at the corrected age of 40 weeks have mild hypermetropia compared to the moderate hypermetropia found in term babies (a difference of 50\%), and they have higher and steeper keratometric values. The greater corneal curvature may contribute to the development of myopia. Ophthalmologists and parents need to be aware of the possibility of visual dysfunction already very early in life even in relatively older premature infants.
\end{abstract}

$\mathrm{F}$ ull term infants are usually hypermetropic, ${ }^{1-3}$ whereas premature babies, with or without previous retinopathy of prematurity (ROP), more often have myopia and astigmatism. ${ }^{4-22}$ The risk of myopia increases in the presence of ROP, and its magnitude increases with a decrease in the age of prematurity and an increase in severity of the residua of ROP. ${ }^{15-25}$ The underlying mechanisms of myopia in premature infants are not well understood, and factors that may have a role, alone or in combination, include an increase in corneal curvature power, ${ }^{26} 27$ axial elongation, ${ }^{28-30}$ or decrease in anterior chamber depth, and higher refractive power of the lens. ${ }^{15}$

The majority of longitudinal and cross sectional studies conducted so far comparing refractive status and keratometric values between premature and full term babies used samples aged from 3 months after term date ${ }^{31}$ to 10 years. ${ }^{13}$ However, to the best of our knowledge, the refractive status and keratometric values of premature babies at 40 weeks' corrected age have not been addressed to date. In the present study refraction and keratometric values of premature babies at 40 weeks' postconceptional age (PCA) were compared to normal term babies at the same age to determine if there were inborn refractive changes presenting as early as 40 weeks of age. In addition, we evaluated the possible relation of birth weight (BW) and gestational age (GA) in premature infants with their refraction and keratometry findings.

\section{PATIENTS AND METHODS}

All consecutive premature infants born at Rabin Medical Center and hospitalised in the neonatal care unit of Schneider Children's Medical Center of Israel between January and March 2002 underwent first funduscopy examination at $4-5$ weeks after delivery. Those with ROP stage 2 or higher with plus disease were excluded from the study. At 40 weeks' PCA, the fundus was re-examined, and the babies with no ROP or with ROP stage 1 to 2 without plus disease were enrolled in the study. Babies with other ocular abnormalities, developmental delay, neurological anomalies, or any other syndrome were excluded. The 33 healthy eligible preterm babies (66 eyes) were matched for PCA with 33 consecutive healthy babies ( 66 eyes) born at term within the same period of time and hospitalised in the neonatal unit, who met the same exclusion criteria. The study protocol was approved by the institutional ethics committee and written informed consent was obtained from the parents.

All the babies underwent a single ophthalmic examination at the age of 40 weeks by the same paediatric ophthalmologist (MS). The examination technique and instruments were similar for both the study and control groups and included cycloplegic retinoscopy and funduscopy, after two instillations at a 10 minute interval of cyclopentolate $0.5 \%$ and phenylephrine $2.5 \%$ drops, and bilateral keratometric measurements ( $\mathrm{k}$ readings) in the horizontal and vertical meridians with an autokeratometer (Nidek KM500, Japan). The refractive values, including astigmatic power (plus cylinder) and axis, were converted to spherical equivalents, and the keratometric values were expressed as the mean of the flattest and steepest meridian in dioptres (D) in each eye. The funduscopy results of the preterm babies were classified according to the international classification of ROP. ${ }^{32}$ The mean refraction and keratometry values in each subgroup of babies were calculated and compared. In the premature subgroup, we also examined the correlation between BW and

Abbreviations: BW, birth weight; GA, gestational age; PCA, postconceptional age; $R O P$, retinopathy of prematurity 


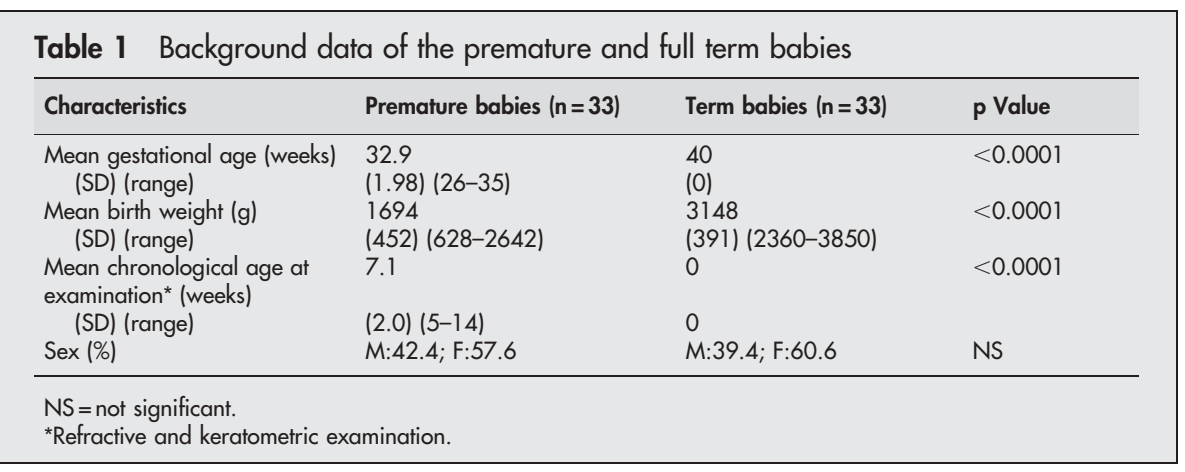

GA with the four ocular parameters of refraction, astigmatism, axis of astigmatism, and keratometric reading.

Student's $t$ test was used to statistically analyse differences between the subgroups in general clinical and refractive parameters. The Mann-Whitney non-parametric test was used to compare the means of the four ocular parameters in the right and left eyes within each group and between groups, as these variables were not normally distributed. In addition, we also tested the medians to achieve a better estimation of the central tendency of these four parameters, and calculated the differences in the medians between the two groups and the 95\% confidence intervals (95\% CI). A $\mathrm{p}$ value of $\leqslant 0.05$ was considered significant. Linear regression analysis and Pearson correlation were used to evaluate the correlation between BW and GA to the ocular parameters in the preterm group. The Statistical Package for the Social Science (SPSS; Professional Statistics, release 10/2000, SPSS Inc, Chicago, IL, USA) was used for all statistical calculations.

\section{RESULTS}

The patients' clinical characteristics are presented in table 1. There was a statistically significant difference between the two groups in mean GA and BW ( $<<0.0001$ for both).

The retinal vascular findings are presented in table 2 . ROP stage 1 to 2 was noted in the majority of the premature babies $(88 \%)$ on the first funduscopy examination, but only in $36 \%$ by the corrected age of 40 weeks $(p=0.001)$.

Mean cycloplegic refraction, in spherical equivalents (SE) (table 3 ), in the premature group was +1.36 (1.16) D in the right eye and $+1.39(1.22) \mathrm{D}$ in the left eye, and in the term group, $+2.40(2.27) \mathrm{D}$ in the right eye and $+2.58(2.33) \mathrm{D}$ in the left eye; this difference was statistically significant $(\mathrm{p}=0.001$ right eye, $\mathrm{p}=0.0002$ left eye). The median value in the preterm group was $1.5 \mathrm{D}$ (95\% CI 1.08 to 1.67 ) $(\mathrm{p}<0.0001)$ and $2.9 \mathrm{D}(95 \% \mathrm{CI} 1.94$ to 3.07$)$ in the term group. In both groups, mean astigmatism (measured in plus cylinder) was less than $1.00 \mathrm{D}$, and it was lower in the preterm babies. Only three patients (four eyes) had more than $1.00 \mathrm{D}$ astigmatism (range +1.25 to $+2.00 \mathrm{D}$ ). There was no statistical between group difference in mean astigmatism $(\mathrm{p}=0.43$ right eye, $\mathrm{p}=0.27$ left eye) or mean axis of astigmatism ( $p=0.4$ right eye, $p=0.6$ left eye). The same results were true with the median astigmatism $(p=0.73)$ or median axis of astigmatism $(\mathrm{p}=0.73)$ (table 3$)$. When the axis of astigmatism was divided into three classes $\left(0-60^{\circ}, 61-\right.$ $120^{\circ}, 121-180^{\circ}$ ) (table 4$)$, a similar distribution was noted in the two groups, with most of the babies having values between $1^{\circ}$ and $120^{\circ}$. Mean keratometric reading (table 3 ) in the premature group was 49.46 (1.73) D in the right eye and 49.43 (1.63) $\mathrm{D}$ in the left eye, and in the term group, 48.08 (1.56) $\mathrm{D}$ in the right eye and 47.96 (1.86) D in the left eye; this difference was statistically significant for each eye between the groups ( $p=0.002$ right eye, $p=0.001$ left eye). Median value in the preterm group was $49.5 \mathrm{D}(95 \% \mathrm{CI}$ 49.00-49.90) and $47.75 \mathrm{D}(95 \%$ CI 47.60-48.40) in the term group $(\mathrm{p}<0.0001)$. Within group comparisons between the right and left eyes yielded no statistically significant difference in any of the parameters.

On Pearson correlation analysis, there was no correlation between GA or BW and the four refractive parameters in right and left eyes in the premature group. To determine whether the variance in any parameter could be explained by the GA or BW, we used linear regression analysis. The results showed that GA and BW had no impact on the refractive and keratometry findings in the right and left eyes in the preterm babies at 40 weeks' PCA.

\section{DISCUSSION}

The increasing survival rate of premature infants has led to an increase in long term ocular problems, such as ROP and its sequelae-refractive errors, strabismus, and amblyopia. ${ }^{4-22} 3031$

Myopia is a common finding in premature infants, and its incidence increases with lower gestational age and the severity of ROP. ${ }^{15-25}{ }^{28-33}$ Holmström et $a l^{8}$ pointed out that even in premature infants without ROP, the risk of myopia and anisometropia is higher than in full term infants: the overall incidence of myopia in their preterm babies was $8 \%$ at the corrected age of 6 months and $10 \%$ at 30 months. The rate of occurrence of myopia was higher in eyes with ROP than eyes without, and higher in the more premature infants.

Choi $e t a l^{15}$ and Lue et al ${ }^{19}$ reported that in premature infants, myopia begins to appear at 6 months of age and increases in severity between ages 6 months and 3 years. Eyes with ROP are more susceptible to a dramatic change in

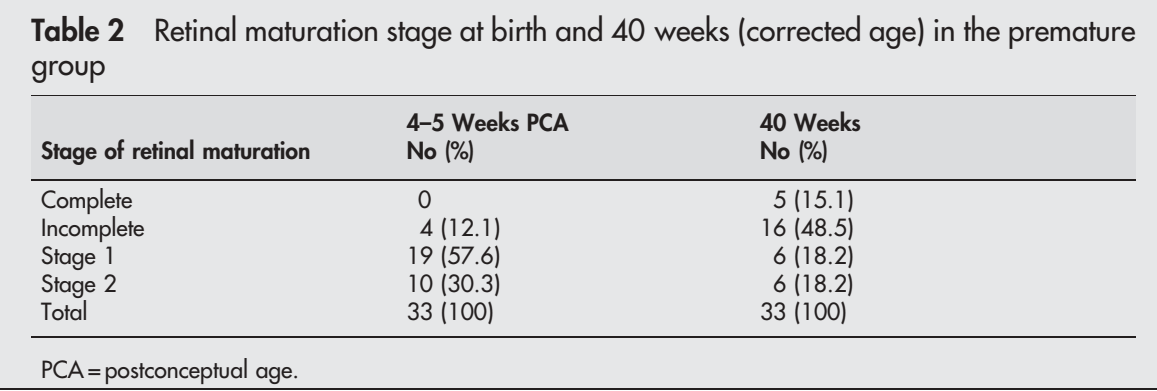


Table 3 Comparison of mean refraction, astigmatism, axis of astigmatism, and keratometric value between premature and term infants

\begin{tabular}{|c|c|c|}
\hline \multirow[b]{2}{*}{ Ocular parameter* } & Premature babies & Term babies \\
\hline & Right & Right \\
\hline Refraction (D)† & $\begin{array}{lr}1.36(1.16) & 1.39(1.22) \\
\text { median } 1.5 ; 95 \% \mathrm{Cl}(1.08 \text { to } 1.67)^{* *}\end{array}$ & $\begin{array}{l}2.4(2.27) \\
\text { median } 2.9 ; 95 \% \mathrm{Cl}(1.94 \text { to } 3.07)^{* *}(2.33)\end{array}$ \\
\hline Astigmatism (D) $\ddagger$ (plus cylinder) & $\begin{array}{l}0.32(0.6) \quad 0.33(0.6) \\
\text { median } 0.4 ; 95 \% \mathrm{Cl}(0.19 \text { to } 0.46) \mathrm{t \dagger}\end{array}$ & $\begin{array}{l}0.51(0.55) \\
\text { median } 0.5 ; 95 \% \mathrm{Cl}(0.40 \text { to } 0.66)+\mathrm{t \dagger}^{-}\end{array}$ \\
\hline Axis of astigmatism (degrees)§ & $\begin{array}{lc}50.3(50.0) & 64.2(58.5) \\
\text { median } 67.5 ; 95 \% \mathrm{Cl}(43.90 \text { to } 70.65) \ddagger \ddagger\end{array}$ & $\begin{array}{l}68.0(63.8) \\
\text { median } 72.5 ; 95 \% \mathrm{Cl}(47.00 \text { to } 76.40) \pm \ddagger\end{array}$ \\
\hline Keratometric reading (D) & $\begin{array}{l}49.46(1.73) \quad 49.43(1.63) \\
\text { median } 49.5 ; 95 \% \mathrm{Cl}(49.00 \text { to } 49.90) \S \S\end{array}$ & $\begin{array}{l}48.08(1.56) \\
\text { median } 47.75 ; 95 \% \mathrm{Cl}(47.60 \text { to } 48.40) \S \S\end{array}$ \\
\hline \multicolumn{3}{|c|}{ 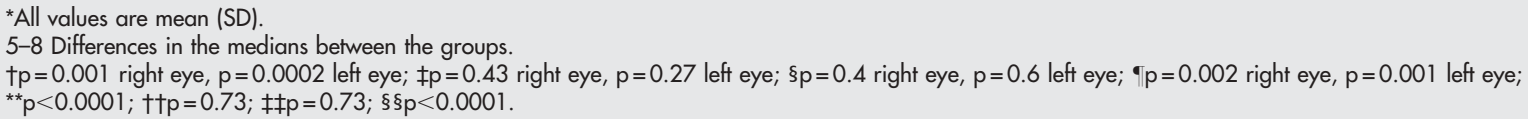 } \\
\hline
\end{tabular}

refractive status after 6 months of age, with no further progress after 3 years.

Full term babies usually have moderate hypermetropia during the first 3 years of life with a bell shaped curve distribution and a steady decline in hyperopic refraction throughout childhood. ${ }^{1-3}$ In the present prospective study we detected only mild hyperopia in the premature group at 40 weeks' PCA; refraction (in dioptres) was $50 \%$ less than in the full term babies at the same age $(p=0.001$ right eye, $\mathrm{p}=0.002$ left eye). These findings may indicate a myopic tendency in premature babies starting as early as 40 weeks' PCA. To the best of our knowledge, these findings for this early age have not been reported to date.

There are several hypotheses explaining the increased rate of myopia in eyes with ROP. Fielder $e^{2} a^{34}$ suggested that myopia of prematurity may be due to the failure of the cornea to flatten in the cooler extrauterine environment. This theory is consistent with a report by Fledelius and Greisen" indicating an increase in corneal curvature in low birthweight children regardless of ROP status. Majima ${ }^{35}$ and Hibino et al ${ }^{4}$ reported that children with retinal residua of ROP had myopia as a result of a combination of increased axial length, lens thickness, and decreased anterior chamber depth. Donzis et $a l^{36}{ }^{37}$ proved that myopia was caused by high crystalline lens power, and Hittner $e t \mathrm{al}^{24}$ demonstrated shallowing of the anterior chamber in myopic eyes with ROP residua. The refraction of the premature group could have been influenced by the ROP since the neural retina is a controller of eye growth and refractive development. Fulton et $a^{38}$ demonstrated that rod photoreceptors and phototransduction (neural retina) are involved in ROP. According to Reisner $e^{2}$ al $^{39}$ the role of rod mediated retinal function in the regulation of eye growth in children with mild ROP is supported by their finding of an association of abnormal and rod mediated retinal sensitivity and refractive development. Animal models of myopia have focused on the ocular biochemical mechanisms involving vasoactive intestinal polypeptide (VIP) and dopamine..$^{40}{ }^{41}$ Raviola and Wiesel,,$^{40}$ in a study in monkeys, showed that abnormal visual input leads to excessive expansion of the posterior segment of the eye as well as an increase in retinal VIP. They proved that an increased VIP level is related to the abnormal axial elongation caused by lid fusion, which is an important factor in the development of myopia. Using a chicken model, Stone et $a l^{41}$ observed a reduced concentration of dopamine and its metabolites in myopic eyes compared to control eyes, and Wildsoet and Pettigrew $^{42}$ reported on the impact of kainic acid on eye enlargement, showing that local administration of apomorphine decreases the axial elongation. Also in chickens, Troilo and Wallman ${ }^{43}$ and Troilo et $a l^{44}$ noted that it was the refractive error that guided the eye towards emmetropia rather than eye size, and that the shape related mechanism controlled eye growth. Both these two mechanisms function within the eye (retinal ganglion cells) and the brain.

Our results for astigmatic values and the axis of astigmatism differ from those in the ophthalmic literature. In both groups, mean astigmatism was less than $1 \mathrm{D}$, but it was lower in the preterm than the full term babies $(p=0.43$ right eye, $\mathrm{p}=0.27$ left eye). Moreover, within both groups, for both eyes, differences in mean axis of astigmatism and in the three classes of astigmatism $\left(0-60^{\circ}, 61-120^{\circ}\right.$, and $121-180^{\circ}$ ) were non-significant. These findings might be attributable to the older gestational age of our premature babies (32-33 weeks) compared to the samples reported in the literature.

Holmström et $a l^{8}$ found a decrease in astigmatic values between the 6 month and 30 month examinations. Astigmatism of $\geqslant 1 \mathrm{D}$ was more frequently found in eyes with ROP than in eyes without, but not in eyes with cryotreated ROP. Quinn et $a l^{5}$ demonstrated that the incidences of myopia and high myopia were higher in infants with anisometropia or astigmatism than in infants without these refractive abnormalities. A higher incidence of astigmatism was associated with more severe ROP. The incidence decreased significantly between the third and 12th month examinations.

Table 4 Distribution of axis of astigmatism in both groups

\begin{tabular}{|c|c|c|c|c|}
\hline \multirow[b]{2}{*}{ Astigmatism (plus cylinder) } & \multicolumn{2}{|c|}{ Premature babies $(n=33)$} & \multicolumn{2}{|c|}{ Term babies $(n=33)$} \\
\hline & Right eye (\%) & Left eye (\%) & Right eye (\%) & Left eye (\%) \\
\hline $\begin{array}{l}0-60^{\circ} \\
61-120^{\circ} \\
121-180^{\circ} \\
\text { Total }\end{array}$ & $\begin{aligned} 18(55) \\
14(42) \\
1(3) \\
33(100)\end{aligned}$ & $\begin{array}{c}14(42) \\
13(39) \\
6(18) \\
33(100)\end{array}$ & $\begin{array}{c}14(42) \\
13(39) \\
6(18) \\
33(100)\end{array}$ & $\begin{array}{c}17(52) \\
14(42) \\
2(6) \\
33(100)\end{array}$ \\
\hline
\end{tabular}


Corneal curvature (keratometric power/reading) is a determinant factor in the refractive results and visual acuity. It is usually steep in newborn infants, and steeper in premature infants. ${ }^{45-47}$ Donzis et $a l^{36}{ }^{37}$ demonstrated a longitudinal decrease (rapid flattening) in the corneal curvature in eyes of premature babies born at 28-34 weeks GA, starting from the last few months of gestation and continuing for the first 3 months of life. Inagaki et $a l^{45}{ }^{46}$ reported mean keratometric readings of 49.5 (1.82) $\mathrm{D}$ in premature babies aged 2 weeks after birth, at a mean GA of 36.4 (1.8) weeks, compared to 47.0 (1.19) D for full term babies aged 2 weeks $(\mathrm{p}<0.01)$. Yamamoto et $\mathrm{al}^{26}$ noted a mean corneal curvature of $50.75 \mathrm{D}$ in premature infants compared to $48.06 \mathrm{D}$ in mature babies, with an increase in keratometric value concomitant with an increase in the severity of ROP. Fledelius, ${ }^{22}$ in a 7-9 year follow up study, found that the corneal radius of curvature was high in premature babies with or without ROP. They suggested that the development of the anterior eye segment was significantly influenced by the preterm delivery.

In our study, keratometric readings were done at age 40 weeks in both full term and premature babies (corrected age), and a significant statistical difference between the groups was found in both eyes $(p=0.002$ right eye, $p=0.002$ left eye). Thus, the difference in the keratometric value may be one of the factors contributing to the development myopia of prematurity.

In our preterm babies, there was no correlation between the refractive parameters and either BW or GA. Previous studies, however, reported conflicting results. Although Holmström et $a l^{8}$ found no correlation among GA, BW, presence of intraventricular haemorrhages and neurological sequelae, and stage of ROP with refractive measurements (spherical equivalents) on logistic multiple regression analysis, BW was clearly associated with astigmatism. Saw and Chew ${ }^{17}$ noted no relation between astigmatism and low BW or prematurity, and Quinn et al ${ }^{12}$ reported that BW, shorter gestation, and increasing severity of ROP were the only statistically significant variables related to the development of myopia and high myopia. However, the gestational ages and birth weights of infants in the study of Quinn et al ${ }^{12}$ were much lower than those of the infants in the present study. Also, the distribution of birth weights and gestational ages in the earlier report was probably broader, which would make detection of a correlation more likely than in the present study.

In our study we included consecutive premature and term babies at 40 weeks' PCA. In order to minimise biases arising from the nature of selection of these babies, we excluded those with abnormalities, developmental delay, neurological anomalies, and other syndromes in both groups.

In conclusion, our study revealed interesting aspects of anatomical and refractive development during eye growth in premature infants at the corrected age of 40 weeks compared with normal full term infants. Our results for refraction, astigmatism, axis of astigmatism, and keratometric readings indicate that premature babies have only mild hypermetropia compared with full term babies, and they have higher and steeper keratometric values. We suggest that the keratometric value may be a contributing factor in the development of myopia in premature infants. The lack of a correlation of GA and BW with the four visual parameters might be related to the relatively high mean gestational age of our preterm babies (32-33 weeks). However, we cannot exclude a role for environmental and metabolic factors in this early myopic shift. Additionally, study of a larger series in the future would clarify several results and conclusions.

These results show that premature infants without plus disease have mild hypermetropia compared with the moderate hypermetropia in term babies and are therefore at risk of developing very early myopia. Both ophthalmologists and parents need to be aware of possible ocular and visual dysfunctions in premature infants already very early in life.

\section{Authors' affiliations}

M Snir, R Friling, I Sherf, Pediatric Ophthalmology Unit, Schneider Children's Medical Center of Israel, Israel

M Snir, D Weinberger, R Axer-Siegel, Department of Ophthalmology,

Rabin Medical Center, Beilinson Campus, Petah Tiqva, and Sackler

Faculty of Medicine, Tel Aviv University, Tel Aviv, Israel

\section{REFERENCES}

1 Brown EVL. Net average yearly changes in refraction of atropinized eyes from birth to middle life. Arch Ophthalmol 1939;19:719-22.

2 Cook RC, Glasscock RE. Refractive and ocular findings in the newborn Am J Ophthalmol 1951;34:1407-9.

3 Larsen JS. The sagittal growth of the eye. IV. Ultrasonic measurement of the axial length of the eye from birth to puberty. Acta Ophthalmol 1971:49:873-8.

4 Hibino Y, Takahashi M, Majima A. Studies on ocular functions of cicatricial retinopathy of prematurity. Measurements of refractive elements. Jpn J Clin Ophthalmol 1978;32:655-62.

5 Quinn GE, Dobson V, Siatkowski RM, et al. Does cryotherapy affect refractive error? Results from treated versus control eyes in the Cryotherapy for Retinopathy of Prematurity Trial. Ophthalmology 2001;108:343-7.

6 Fulton AB, Hansen RM, Petersen RA. The relation of myopia and astigmatism in developing eyes. Ophthalmology 1982;89:298-301.

7 Gordon RA. Donzis PB. Myopia associated with retinopathy of prematurity. Ophthalmology 1986;93:1593-8.

8 Holmström G, el Azazi M, Kugelberg U. Ophthalmological long term follow up of preterm infants: a population based, prospective study of the refraction and its development. BrJ Ophthalmol 1998:82:1265-71.

9 Fledelius HC, Greisen G. Very pre-term birth and visual impairment. Acta Ophthalmol 1993;210(Suppl):63-5.

10 Abrahamsson M, Fabian G, Sjöstrand J. A longitudinal study of a populationbased sample of astigmatic children. II. The changeability of anismetropia. Acta Ophthalmol 1990;68:435-40

11 Gallo JE, Fagerholm P. Low-grade myopia in children with regressed retinopathy of prematurity. Acta Ophthalmol 1993;71:519-23.

12 Quinn G, Dobson V, Repka M, et al. Development of myopia in infants with birth weights less than 1251 grams. Ophthalmology 1992;99:329-40.

13 Fledelius HC. Preterm delivery and subsequent ocular development. A 7-10 year follow-up of children screened in 1982-1984 for ROP. 4. Oculometric and other metric considerations. Acta Ophthalmol Scand 1996;74:301-5.

14 Schalii-Delfos NE, de Graaf MEL, Treffers WF, et al. Long term follow up of premature infants: detection of strabismus, amblyopia, and refractive errors. Br J Ophthalmol 2000;84:963-7.

15 Choi MY, Park IK, Yu YS. Long-term refractive outcome in eyes of preterm infants with and without retinopathy of prematurity: comparison of keratometric value, axial length, anterior chamber depth, and lens thickness. Br J Ophthalmol 2000;84:138-43.

16 Khwarg SI, Yu HG, Yu YS. Change of refraction in premature infants after cryotherapy for retinopathy of prematurity between the age of six months and three years. Korean J Ophthalmol 1995;9:111-6.

17 Saw SM, Chew SJ. Myopia in children born premature or with low birth weight. Acta Ophthalmol Scand 1997;75:548-50.

18 O'Brien C, Clark D. Ocular biometry in preterm infants without retinopathy of prematurity. Eye 1994;8:662-5.

19 Lue CL, Hansen RM, Reisner DS, et al. The course of myopia in children with mild retinopathy of prematurity. Vis Res 1995;35:1329-35.

20 Connolly BP, Eugene YJ, McNamara JA, et al. A comparison of laser photocoagulation with cryotherapy for threshold retinopathy of prematurity at 10 years. Part 2: Refractive outcome. Am Acad Ophthalmol 2002;109:936-41.

21 Gordon RA, Donzis PB. Refractive development of the human eye. Arch Ophthalmol 1985;103:785-9.

22 Fledelius HC. Myopia of prematurity, clinical patterns. A follow-up of Danish children now aged 3-9 years. Acta Ophthalmol 1995;73:402-6.

23 Ingram RM, Barr A. Changes in refraction between the ages of 1 and $3 \frac{1}{2}$ years. Br J Ophthalmol 1979;63:339-42.

24 Hitner HM, Rhodes LM, McPherson AR. Anterior segment abnormalities in cicatricial retinopathy of prematurity. Ophthalmology 1979;86:803-16.

25 Palmer EA, Flynn JT, Hardy RJ, et al. Incidence and early course of retinopathy of prematurity. The Cryotherapy for Retinopathy of Prematurity Cooperative Group. Ophthalmology 1991;98:1628-40.

26 Yamamoto M, Bun J, Okuda T. Corneal curvature in children. J Jpn Contact Lens Soc 1981;23:89-92.

27 Yuji I. The rapid change of corneal curvature in the neonatal period and infancy. Arch Ophthalmol 1986; 104:1026-7.

28 Kent $D$, Pennie $F$, Laws $D$, et al. The influence of retinopathy of prematurity on ocular growth. Eye 2000;14:23-9.

29 Fledelius HC. Preterm delivery and the growth of the eye. An oculometric study of eye size around term-time. Acta Ophthalmol 1992;204(Suppl):10-5. 
30 Gallo JE, Lennerstrand G. A population-based study of ocular abnormalities in premature children aged 5 to 10 years. Am J Ophthalmol 1991;111:539-47.

31 Cryotherapy for Retinopathy of Prematurity Cooperative Group. Multicenter trial of cryotherapy for retinopathy of prematurity. Three-month outcome. Arch Ophthalmol 1990;108:195-204.

32 Graham MV, Gray OP. Refraction of premature babies' eyes. BMJ 1963;1:1452-4.

33 The Committee for Classification of Retinopathy of Prematurity. An internationa classification of retinopathy of prematurity. Arch Ophthalmol 1984;102:1130-4.

34 Fielder AR, Levene MI, Russell-Eggitt IM, et al. Temperature-a factor in ocula development? Dev Med Child Neurol 1986;28:279-84.

35 Majima A. Studies on retinopathy of prematurity. II. Fundus appearance and ocular functions in cicatricial phase of very low birth weight infants. Jpn J Ophthalmol 1977;21:421-35.

36 Donzis PB, Insler MS, Gordon RA. Corneal curvatures in premature infants. Am J Ophthalmol 1985;99:213-5.

37 Donzis PB, Insler MS, Gordon RA. Corneal curvatures in premature infants. Am J Ophthalmol 1984;98:627-8.

38 Fulton AB, Hansen RM, Petersen RA, et al. The rod photoreceptors in retinopathy of prematurity: an electroretinographic study. Arch Ophthalmol 2001;119:499-505.
39 Reisner DS, Hansen RM, Findl O, et al. Dark-adapted thresholds in children with histories of mild retinopathy of prematurity. Invest Ophthalmol Vis Sci 1997;38:1175-83.

40 Raviola E, Wiesel T. Neural control of eye growth and experimental myopia in primates. Ciba Foundation Symposium 155. In: Myopia and the control of eyegrowth. Chichester: Wiley and Sons, 1990:22-44.

41 Stone RA, Lin T, Laties AM, et al. Retinal dopamine and form-deprivation myopia. Proc Natl Acad Sci USA 1989;86:704-6

42 Wildsoet C, Pettigrew J. Kainic acid-induced eye enlargement in chickens: differential effects on anterior and posterior segments. Invest Ophthalmol Vis Sci 1988;29:311-9.

43 Troilo D, Wallman $j$. The regulation of eye growth and refractive state: an experimental study of emmetropization. Vis Res 1991;31:1237-50.

44 Troilo D, Gottleib MD, Wallman J. Visual deprivation causes myopia in chicks with optic nerve section. Curr Eye Res 1987;6:993-9.

45 Inagaki $Y$. The rapid change of corneal curvature in the neonatal period and infancy. Arch Ophthalmol 1986;104:1026-7.

46 Inagaki Y, Tanaka M, Hirano A, et al. Rearranged automated keratometer for newborn infants and patients in the supine position. Am J Ophthalmol 1985;99:664-6.

47 Ehlers N, Sorensen T, Bramsen L. Control corneal thickness in newborns and children. Acta Ophthalmol 1976;54:285-90. 